\title{
Frozen Section Diagnosis
}

National Cancer Institute

\section{Source}

National Cancer Institute. Frozen Section Diagnosis. NCI Thesaurus. Code C49338.

A method for rapid diagnosis that uses a frozen tissue sample rather than a chemically fixed sample. 